Journal of Animal and Veterinary Advances 11 (4): 458-461, 2012

ISSN: $1680-5593$

(C) Medwell Journals, 2012

\title{
A Comparative Analysis of the Effects of Garlic, Elderberry and Black Seed Extract on the Immune System in Mice
}

\author{
Mehrdad Modaresi \\ Department of Agriculture, Islamic Azad University, Khorasgan Branch, Esfahan, Iran
}

\begin{abstract}
The herbs garlic, elderberry, black seed have acknowledged therapeutic use in traditional medicine. With their immune-effective compounds, they are of much application in the traditional treatment of infections, the present study attempts a comparative investigation of the roles of the aforementioned herbs in the immune system and blood proteins. In this study, the mice of the $\mathrm{Balb} / \mathrm{C}$ genus were divided into four groups: control, 1,2 and 3 . Each of these received $50,100,200 \mathrm{mg} \mathrm{kg}^{-1}$ of garlic, elderberry and black seed extracts, respectively. The extract was injected using the Inner Peritoneum (IP) Method every other day for 20 days. At the end of the experiments, blood samples were taken to conduct a count of white blood cells and an electrophoresis of blood proteins. The results were evaluated through SPSS at a $\mathrm{p}<0.05$ level. The analysis indicates that black seed and garlic extract were able to increase the number of white blood cells. While black seed gave rise to the amount of white blood cells and also caused the albumin, alpha 1 and 2 proteins and the $\mathrm{A} / \mathrm{G}$ ratio to increase, garlic was effective in raising alpha 1 and gamma globulin levels. This is in contrast with elderberry which plays a significant role in decreasing the gamma protein's density. The two herbs, garlic and black seed, impressed the immune system through changing the density of such blood proteins albumin, alpha 1 and 2 and altering the number of white blood cells whereas the result suggest no significant effect in the case of elderberry.
\end{abstract}

$\underline{\text { Key words: Black seed, garlic, elderberry, immune system, mice, Iran }}$

\section{INTRODUCTION}

Herbal or traditional medicine dating to the time of the ancient Greeks was one way of treating different illnesses for years on end. Realizing the potentially dangerous side effects of chemical drugs, the researchers are witnessing a return of emphasis on herbal medicine. Garlic, black seed and elderberry are considered as able to reinforce the immune system against infection however, no knowledge is available regarding their effective dose and proper application.

Black seed, scientifically called Nigella sativa is part of the Rununculacenae family, it is a weed with single year life-span and optimally grows warm and dry regions. It was planted in the warmer countries from ancient times and its place of origin is in southern Europe and West Asia. It is the seed of black seed that is used therapeutically. Its fruit is cylindrical in shape and bears black, aromatic seeds. This plant has been considered a herb for $>2000$ years and in Egypt it dates back to 3000 years ago: it was discovered scattered inside the tombs of Egyptian kings. Black seed is added to food as a spice or additive in most countries and has numerous therapeutic effects (Vahdati-Mashhadian et al., 2005). In India, spices have been used as drugs since times immemorial; one of these, black seed, acts as a strong antimicrobial agent against Sacchoromyces, E. coli, Bacinus subtils Cerevisiae. Black seed also possesses an extensive spectrum of therapeutic properties including: antimicrobial, antitumor, antiviral and antioxidant. Moreover, it causes muscles to relax (Paradise, 2005). Furthermore, the seed of this herb has such wide ranging effects as anti-parasite, antibacterial, antifungal; it also regulates menstruation, increases milk production, fights inflammation and is an analgesic (Merat and Fallahzadeh, 1996).

Garlic is scientifically called Allium sativum is a member of the Liliaceae family (Jesse et al., 1997). This plant has a long history as a herb, it was prescribed as a diuretic in the times of Hippocrates. Garlic is considered as having antiseptic, anti-cancerous and antibacterial properties and contributing to food digestion, appetite, the healing of wounds and sores, lowering the blood pressure (Lau et al., 1983).

Garlic contains numerous compounds such as mineral vitamins, enzymes, sulfurous compounds, amino-acids and antioxidants such as selenium (Santos, 1995). In fact garlic produces allicin through enzyme reactions to protect itself from insects attacking it therefore, Allicin could be considered an insect-repellant substance in plants. Allicin was first discovered by Cavallito in 1994 who found out about its antimicrobial effects for the first 
time (Koscicnly et al., 1999). Garlic's preservative effects against arthrosclerosis is perhaps related to its ability to reduce the lipid content of the arteries (Koscicnly et al., 1999; Celermajer et al., 1994). It appears that the human LDL serum gains significant resistance to oxidation after the intake of liquid garlic extract (Jepson et al., 2000). It's been proven that allicin is effective against free radicals and acts as an antioxidant (Dugenci et al., 2003).

Elderberry scientifically called Sambucus nigra has been used by the people since old times to treat different diseases. Its leaves are green, oval, indented and an integration of 5-7 smaller leaves. If the leaves are broken and rubbed, an unpleasant odor will ensue. Its flowers are white and in clusters and appear in late spring. The fruits of elderberry is fleshy, small like grapes and of a dark blue color. Of the parts of this plant, the ones used are the flowers, leaves and the inner skin of the stems. The bark and leaves of this bush contain such substances elderberry sambucine, sambunigerine, choline, cicutine and a small amount of potassium nitrate. Its flowers contain elderline and a small amount of essence. The fruit of elderberry contains chrysanthemin, sugars, essence, valerenic acid and acetic acid. The cicutine obtained from this plant improves the immune system of the healthy person and is also effective in treating rheumatism and infection of the joints. Elderberry is considered to be cause diarrhea and fight constipation and the best drug to treat constipation in the elderly and those suffering from weakened bowel contractions. However, there's been a comparative analysis of the effects of garlic, elderberry and black seed on the immune system and blood proteins in laboratory mice.

\section{MATERIALS AND METHODS}

This empirical study was carried out between 2009-2011 in Islamic Azad University of Isfahan. Its protocol was drafted in accordance with international rules and was approved in the university's ethics committee. Male mice of the $B a l b / C$ genus, weighting between 25-30 g which were reared in the Animal Nest of Isfahan University of Medical Sciences were used in this research. The samples were divided and kept in laboratory conditions for 1 month in order to adjust with the environment.

During the phases of adjustment and injection, the mice were kept subjected to natural cycles of light and dark in temperatures between $25-30^{\circ} \mathrm{C}$ and normal moisture and light intensity. They were fed with standard, pre-prepared fodder with no restriction of access to food and water. In the course of this experiment, the mice were categorized into 4 groups of 8 with the following characteristics:
- Control group: this group did not receive any injections and was merely used to obtain SRBC and to be compared with the care groups

- Care group 1: about 10 injections each containing $0.5 \mathrm{cc}$ of hydro-alcoholic extract (garlic, elderberry or black seed) with a $50 \mathrm{mg} \mathrm{kg}^{-1}$ dosages were administered to this group in 20 days (i.e., every other day)

- Care group 2: about 10 injections each containing $0.5 \mathrm{cc}$ of hydro-alcoholic extract (garlic, elderberry or black seed) with a $100 \mathrm{mg} \mathrm{kg}^{-1}$ dosages were administered to this group in 20 days (i.e., every other day)

- Care group 1: about 10 injections each containing $0.5 \mathrm{cc}$ of hydro-alcoholic extract (garlic, elderberry or black seed) with a $200 \mathrm{mg} \mathrm{kg}^{-1}$ dosages were administered to this group in 20 days (i.e., every other day)

In order to stimulate the immune system, a sheep's washed SRBC globule (1\%) was injected to the all samples including control and care groups using the Inner Peritoneum Method and with two intermissions, one between the 5 th and 6 th injection and the other between the 9 th and 10 th.

Analysis of white blood cell levels: A comparison between the WBC numbers in control and care groups revealed a significant rise in the care groups receiving garlic and black seed of all doses.

Results obtained from the analysis of garlic, black seed and elderberry extracts on the electrophoretic pattern of the protein particles in the blood of mice: Figure 1 , respectively shows the electrophoresis of the control and care groups injected with $50 \mathrm{mg} / \mathrm{kg} / 48 \mathrm{~h}$ doses of garlic extract (Fig. 1).

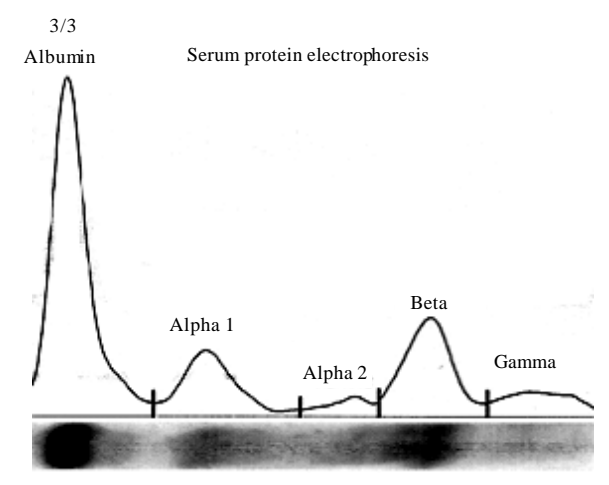

Fig. 1: Electrophoretic pattern of the protein particles in the blood of mice 


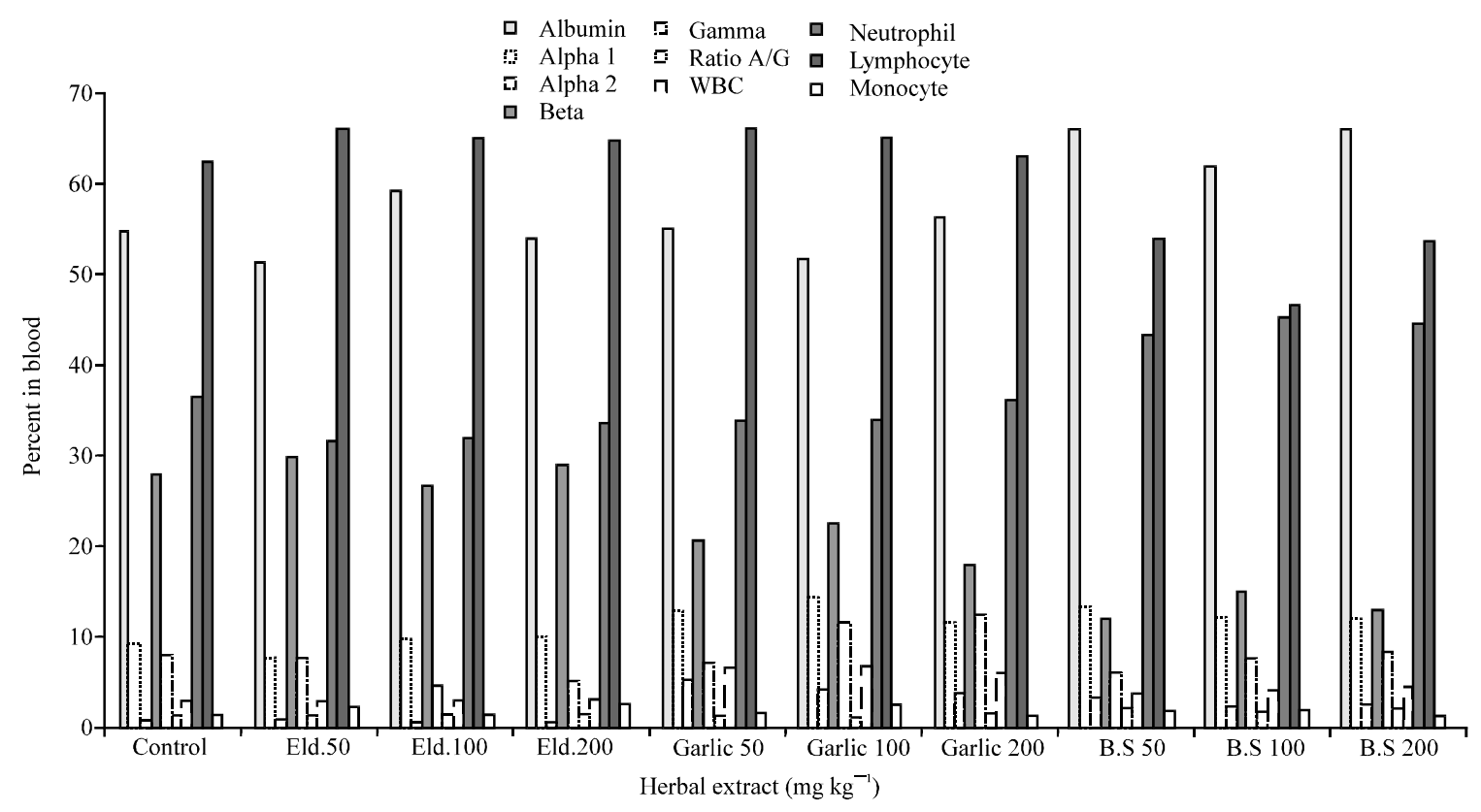

Fig. 2: Results showing the effects of garlic, black seed, elderberry hydro-alcoholic extract on the blood

Analysis of albumin levels in blood: Albumin was measured in the electrophoresis of the plasma of the small laboratory mice and results indicated a significant rise in all three care groups receiving black seed extract compared to the control group with a certainty rate over $95 \%(\mathrm{p}<0.05)$.

Analysis of alpha 1 globulin levels in blood: There is a significant rise in the amount of alpha 1 globulin in the experiment groups receiving garlic and black seed extracts opposed to the control group.

Analysis of alpha 2 globulin levels in blood: An analysis of the alpha 2 globulin levels in the blood of mice belonging to care groups administered with garlic and black seed extracts revealed a significant rise in all doses at a $\mathrm{p}<0.05$ level.

Analysis of beta globulin levels in blood: There is a significant decline in beta globulin levels in the mice of care groups receiving garlic and black seed extracts compared to the control group.

Analysis of gamma globulin levels in blood: A comparison of the amount of gamma globulin present in the control group and the care groups indicated a significant decline of the said protein in care groups 2 and 3 receiving garlic extracts and care groups 2 and 3 administered with elderberry extract. Figure 2 shows the results of this comparison.

\section{RESULTS AND DISCUSSION}

The present study was carried out on the ground of the effects on the immune system attributed to garlic, black seed and elderberry in traditional medicine. Albumin synthesis declines in different illnesses especially in the liver-related illnesses (Dugenci et al., 2003). Thus, the rise of albumin levels in the care groups injected with black seed suggests that not only does black seed intake not cause the destruction of liver tissue but it is also likely to induce and improve liver activity. In this study, the researchers witnessed a significant rise in alpha 1 globulin levels in care groups administered with garlic and black seed. Alpha 1 globulin is mostly made up of alpha 1-antitrypsin (Dugenci et al., 2003). Alpha 1-antitrypsin is one of blood's glico-proteins that proliferates in response to severe attacks but these proliferations are of no diagnostic characteristics since they are not peculiar to any special disease (Dugenci et al., 2003). Using garlic and black seed extracts contributes to a significant rise in alpha 2 globulin in the care groups. In nephrotic syndrome with the smaller proteins destroyed, alpha 2-macro-globulin rises to even 10 times or more, its normal amount. Light weight proteins such as albumin are filtered and expelled along with urine in this syndrome and there is evidence of a decline in alpha 1 globulin and albumin and a surge of alpha 2-macro-globulin levels in the electrophoresis pattern. This is while in the present study, the three factors mentioned have increased as a result of the garlic and black seed extracts intake. The rise of albumin, alpha 1 globulin and alpha 2 globulin in care 
groups administered with garlic and black seed extracts is not likely to have altered the glomeruli capillary. In this research, the researchers witnessed a significant fall in beta globulin levels under the influence of garlic and black seed extracts.

The significant alterations occurring in the amount of immune-globulins under the intake of garlic and black seed extracts suggest that the immune system is stimulated and the injections of the aforementioned substances have caused the receiving groups to respond. While in the case of elderberry extract, the researchers have no evidence of such reactions taking place. Dugenci et al. (2003) studied the stimulating effects of different herbs on the immune system using the Oncorhynchus mykiss species. To this end, the fish were put under a diet of Viscum album, Nettle (Utrica dioica) and ginger (Zingiber officinale) liquid extracts. The fodder consisted of 0.1 and $1 \%$ dry extract of the said herbs per $2 \%$ of the fish's body weight. This was given to the fish on a daily basis for 3 weeks. The Oncorhynchus mykiss demonstrated a significant response in the general immune system in the group receiving $1 \%$ liquid ginger extract. There was also a significant rise in phagocytosis and the external dissolution of blood leukocyte.

The present study on small laboratory mice indicates that the $\mathrm{A} / \mathrm{G}$ ratio underwent a significant rise in the group receiving black seed extract injections. The amount of albumin and globulin and their ratio paints a picture of liver's activities. An increase in albumin levels in samples injected with black seed extract and the rise in $\mathrm{A} / \mathrm{G}$ ratio in this group signify black seed's effects of induction on liver's activity. Albumin synthesis decreases in different diseases especially liver malfunctions and the plasma of those inflicted usually show a decline in the $\mathrm{A} / \mathrm{G}$ ratio. The practitioners of traditional medicine are also of the belief that black seed strengthens the liver and relieves it of complexities.

\section{CONCLUSION}

In a final analysis, the researchers can consider black seed and garlic as herbs affecting the immune system while elderberry does not show any identifiable results.

\section{ACKNOWLEDGEMENTS}

The present study is a result of research commissioned by Islamic Azad University of Isfahan. Here the researchers wish to thank all who helped us in different parts of this project.

\section{REFERENCES}

Celermajer, D.S., K.E. Sorensen, D.J. Spiegelhalter, D. Georgakopoulos, J. Robinson and J.E. Deanfield, 1994. Aging is associated with endothelial dysfunction in healthy men years before the age related decline in women. J. Am. Coll. Cardiol., 24: 471-476.

Dugenci, S.K., N. Arda and A. Candan, 2003. Some medicinal plants as immunostimulant for fish. J. Ethnopharmacol., 88: 99-106.

Jepson, R.G., J. Kleijnen and G.C. Leng, 2000. Garlic for peripheral arterial occlusive disease. Cochrane Syst. Res., 1: 1469-1493.

Jesse, J., M. Mohseni and N. Shah, 1997. Medical attributes of Allium sativum (Garlic). Am. J. Bot., 81: 89-95.

Koscicnly, J., D. Klussendorf and R. Lateza, 1999. The antitrombic effect of garlic. Atheroscience, 144: 237-249.

Lau, B. H.S., M.A. Adetumbi and A. Sanchez, 1983. Allium sativum (garlic) and atherosclerosis: A review. Nutr. Res., 3: 119-128.

Merat, A. and M. Fallahzadeh, 1996. Effect of garlic on some blood lipids and HMG-CoA reductase activity. Iran. J. Med. Sci., 21: 146-151.

Paradise, L.A., 2005. Black cumin seed extract. http://www. answers.com/topic/black-cumin-seed-extract.

Santos, A., 1995. Effects of garlic powder and garlic oil preparations on blood lipieds, blood pressure and well being. Br. J. Clin. Res., 6: 91-106.

Vahdati-Mashhadian, N., H. Rakhshandeh and A. Omidi, 2005. An investigation on LD 50 and subacutehepatic toxicity of Nigella Sativa seed extract in mice. Pharmazie, 60: 544-547. 